\title{
Experiencing Hindustani Raga Music: A Select Study from Kolkata
}

\author{
Sanjoy Bandopadhyay ${ }^{1} \&$ Samidha Vedabala ${ }^{2}$ \\ ${ }^{1}$ Professor, Department of Music, Sikkim University, Sikkim, India \\ Email: sbandopadhyay@cus.ac.in \\ ${ }^{2}$ Assistant Professor, Department of Music, Sikkim University, Sikkim, India \\ Email:svedabala@cus.ac.in
}

\begin{abstract}
The research study is executed to identify the essential musical components that work behind the success of Hindustani Raga Music (HRM) renderings. It examines different performance components of HRM rendered in public concert situations. The traditionally prescribed parts of HRM performances and the music generated effects like raga mood, serenity, liveliness, surprise, and others in performances are also analyzed in the study. The objective of this study is to identify the musical components that are responsible for generating considerable impacts on the listeners. This investigation is based on the rating of different musical components by the listeners. Highly popular HRM festivals were selected for obtaining data. The findings successfully indicate that slow improvisations and traditionally accepted raga moods are the highimpact components for good acceptance by the listeners; also, the applications of high-speed components make the renderings outstanding.
\end{abstract}

Keywords: Hindustani, raga music, mood, speed, serenity, liveliness, uniqueness, surprise

\section{Introduction}

Musical Performance is an act of accomplishment and dissemination of musical ideas to the listeners or audiences. The different genres, forms, and styles of music communicate the concerted musical cognizance, understanding of the structure, and the meaning. Felds' definition of communication is relevant to music too. It is not a 'thing' or 'entity'; rather, it is 'socially interactive' and 'intersubjective' process (Feld, 1984). It bears the attribution of social knowledge that moves from a 'pre-given mindset' to capaciousness (Moran, 2013). Musical skills mastered by the performers through their training, understanding, assimilation, and experiences are demonstrated in performances. The audiences absorb it with their familiarity with the language of the art. It is difficult to predict the impact-output because of the complicated combinations of different musical ingredients. These include; chosen musical contents, applied virtuosity, and the resulted effects at different phases of renderings. The experiences of the performers and the audiences are rarely the same. Hence, what the performer performs has less chance to get interpreted by the audience as it is. Improvisational characteristics remain present in Hindustani raga Music $\left(\mathrm{HRM}^{\mathrm{i}}\right)$ throughout a music recital. The performers go through an in-depth learning process $\left(\right.$ talim $\left.^{i i}\right)$, get familiarize with traditional expressions, get intimately acquainted with different characteristic details of ragas ${ }^{i i i}$, and understand the structurization of different patterns of singing or playing. A particular raga conveys different shades of colors at different times and

(C) AesthetixMS 2020. This Open Access article is published under a Creative Commons Attribution Non-Commercial 4.o International License (http://creativecommons.org/licenses/by-nc/4.o/), which permits non-commercial re-use, distribution, and reproduction in any medium, provided the original work is properly cited. For citation use the DOI. For commercial re-use, please contact editor@rupkatha.com. 
when performed by different individuals. Moreover, the same musician can invoke different effects from a particular raga on different occasions (Palmer, 1997).

A typical HRM performance in vocal or instrumental music inherently carries balance in both the technical and expression components. These components are virtuosity and creativity. Virtuosity components like; speed, rhythmic complexity, complicated ornamentation, sound dynamics carry high importance as the content selection and melodic variations. There are times when the performers render expressive components that put highly virtuous executions to challenge. Such executions influence the aesthetics perception of the listeners and add special meanings to the performances (Sloboda, 2000). In addition to the musical structure, ornamentation, and other musical factors, the extra-musical factors also play significant roles in the success of a musical performance. These include the architecture of the auditorium that plays a vital role in the sound transmission, quality of sound amplification system and their adjustments, stage decoration, light arrangements, concert hosting, and the outfit of the artists. These auxiliaries play vital roles in the success of a concert and influence the performing and listening ${ }^{\text {iv }}$ experiences of both the performers and the audiences.

\section{Performance Structure}

There are different performance structures for vocal form khayal and instrumental music like raga renderings on the sitar, sarod, and other instruments. A standard method of introducing a raga in a khayal performance is usually a slow improvisation without any rhythmic support. This slow improvisation or alAp is mostly followed by a slow composition and then a middle tempo or fast composition. The drum-pair tablA usually provides rhythmic support with the renderings of compositions. On rare occasions, the instrumentalists may opt for rhythmic support on the Pakhawaj when they render in Dhrupad-Dhamar style. However, there exist noticeable differences in styles of elaboration between vocal and instrumental music renderings.

Most of the khyal-schools opt for a brief raga elaboration at the start, which is known as 'AocAr $r^{v \text {, }}$. The detailed raga vistar vii with tablA accompaniment is done in baRAkhayAliii or the slow composition part in the khyal style of vocal rendering. In this part, at a later stage, the ragas get elaborated with fast passages called $t A n a^{i x}$. The slow composition part is followed by fast composition or chotA-khayAl. The faster-paced chotA-khayAl renderings depict more tana passages and less slow vist $A r$.

Instrumental music rendering patterns are mostly based on khayAl and dhrupad styles of singing. The sequence of the first part of the rendering, i.e., the AlAp part, is mostly based on Dhrupad style. Instruments like sitar, sarod, and other string instruments generally follow the dhrupad pattern of Non-Tom $A l A p^{\mathrm{x}}$, which is known as $A l A p$, jod, and $j h A l A$. Blowing instruments like flute recitals generally present a brief aocAr in place of detailed alap. However, there are instances that the musicians opting for different openings to create desired musical impacts. In sitar also sitar payers play Aocar as and when required. Vilambit Gat or slow compositions followed by drut gat or fast compositions are commonly played after AlAp. The silsila or the performance sequence can be different depending on the duration of renditions and the artists' choices. A short performance may take a brief $A o c A r$, followed by a striking fast composition. A concert may also be planned as one long AlAp-jod-jhAlA on one raga followed by a middle tempo composition in some other raga and fast composition in some other raga, or some other performance sequence. 


\subsection{Performance and Appreciations}

Music performance is far more than just the structure. It is the semiosis(Martinez,2001) produced by the emotions or feelings, enriched by aesthetical experiences. It is non-conceptual and induces the senses(Eggebrecht, 2010). The said structure perceived by the performer to the experience of the audience adds up different meanings and distinct connotations in each level of rendition. The true interpretation of performance begins after the structure, as Paul Thom termed it, 'how it goes' until 'what it means'(Thom, 2003).

A musical concert has two primary participators, the musicians and the listeners. An HRM performance is mostly improvised. The music output is the result of, (a) the musicians talim[training], (b) analysis and assimilation of the received talim, (c) interpretations of the assimilated musical knowledge, and finally (d) the renderings of the musical imaginations that are the products of the earlier stated phases. The other important component is the extra-musical factors [EMP].

This article has not considered EMP. Extra Musical Factors may include several areas like the music transmission process in the concert situation, preparation of the musicians to be visually impressive, the process of preparing the audiences to receive the music appropriately, and others. Preparing the audiences is mainly done through prior briefings, promotions, and anchoring.

The music reaches from audiences to the listeners. The listeners analyze the received music with

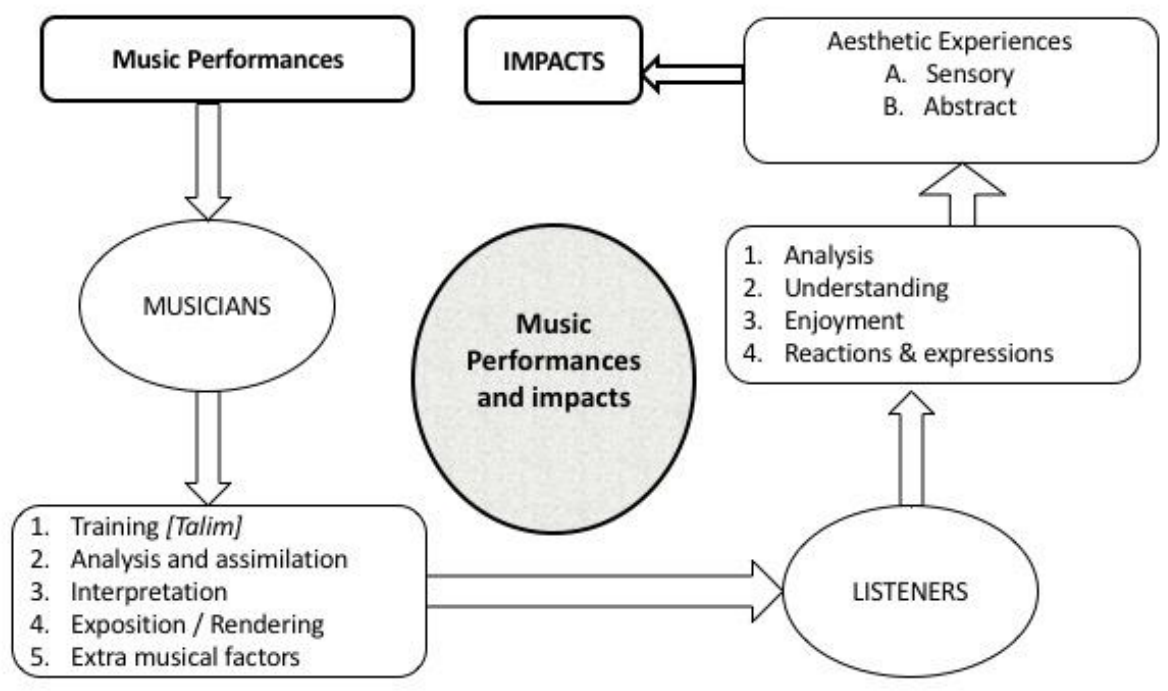

Diagram 1

their understanding and taste; this leads to enjoyment [or frustration], and finally comes the reactions of the listeners. The aesthetic experiences of the listeners may be sensory and abstract. These experiences may be accepted as the impacts of the presented music.

\subsection{Raga moods}

Performing a raga is very much beyond the combination of particular notes, or a mode (many define raga as). Raga is much more than a mode. Each raga is like individual audio personalities. Just the described notes can not even go close in describing a raga. The notes are just the skeleton of a raga; it gets life and flesh through the artistic interpretations of the traditional contents. The musicians know them as bAbat (contents) and tarIkA (way of presentation). The same can come 
out differently when different $\operatorname{tar} I k A$ comes into play. The presentation styles change when performers of different styles and understanding render ragas; this may also depend on the musician's physiological and psychological conditions during the performance.

The audio personality of a raga comes out with its uniqueness at the same time with different interpretations. We witness it when we listen to several renderings of a particular raga by the same or different musicians in different occasions. Of course, there have been theories to describe the raga over the traditionally prescribed parameters like aroh (ascending), avaroh (descending), alpatva (lesser occurrences of a note), bahutva (many occurrences of a note), nyasa (end-note of phrases), or time-association. All these stated items are called raga-lakshana. Raga lakhshanas are the components that appear when raga mood or the unique audio personality inherent to a raga gets created. There are also exceptions in practices in different gharanas, but these applications do not affect the primary raga-mood or the life force of a raga.

\subsection{Uniqueness}

Despite structural and inherent beauty, the unique qualities in a performer are the essential abilities for presenting the portraying styles of a raga. Mostly, the musicians take to the route of some established musicians. However, in some recitals, the listeners identify some uniqueness that is helping in raga rendering, but that may not get widely found in the regular rendering practices of that particular raga. The artists' personal experience, realization, and skills make differences in the performances that appear unusual and surprising to the audiences.

\subsection{Liveliness}

Liveliness should be understood in its general terms. In HRM, the listeners mostly feel liveliness when the musician is in good command over the musical medium. The musical media are vocal or instrumental. Here optimized use of virtuosity with artistry makes the music lively or bright. The uniqueness of an Indian classical music concert, as Pitts writes, is a live interaction between the performer and the audiences (Pitts, 2005). In such concerts, the listeners are not just 'reverent applauder' as Juan Prieto-Rodriguez and Victor referred Baumol and Bowen (1966), Throsby and Withers (1977), Abbe-Decarroux and Grin (1992) pointed out in the context of classical music. In HRM concerts, the educated listeners listen critically, and at the same time, they go on appreciating using verbal expressions like, 'AhA', $k y A b A t h A y$ ', or 'sAdhu' during the renderings. These appreciations make the recitals lively and assist the musicians in going deeper into music.

\subsection{Surprises}

The element of surprise generates when in a raga-rendering, something happens that comes as unexpected and uplifts the music. Surprise here is in a positive sense. It is something solely produced out of the performer's skill and experience. Here the performer does the insertions over the frame of traditional designs. Such surprising factors aesthetically enrich the performance and influence the listener's experience with new acceptable interpretations. The combination of learning through oral transmission and nicely designed intelligent improvisations matching learned materials create such surprises. These are not just entertainment or thrill for the musicians; for them, these are innovations giving new meaning to their music (Christopher D. Azzara Alden H. Snell, 2016). Interestingly, this extraordinary expressive quality makes a performer preferable than another (Juslin, 2003).

\subsection{Serenity}

Serenity again should be understood as it is understood in general life experiences. Music is the expression of emotions (Gabrielsson and Juslin, 2003). Experiences like motion, tension, human 
character, identity, beauty, religious faith, and social conditions (Juslin,2013) relate to the creation and absence of serenity. For establishing musical serenity, the musicians require good command in meaningfully using silence, stretching executions, and effective slow movements in music renderings.

\subsection{Accompaniment}

Free moving, improvisation-based HRM is bounded with cycles of rhythm. Accompaniment in tablA in khayal and instrumental music is something beyond, as Matthew Write and David Wessel stated that a tAla is not "Canned pattern" but much more than that, and the music from both the tabla player and singer are improvised (1998). Both the melodic and the rhythmic harmony in the structural and philosophical levels determines a successful performance. The rhythm and the vocal or instrumental performers complement each other, which creates excitement among the performers and the audience (Moran, 2011).

\section{Methodology}

The overall design of the research study has adopted digital ethnography as the primary strategy in the collection of data. A Semi-structured questionnaire was designed with the constructs of the research problem and distributed through a website. Random sampling was used in this study. Seventy-six listeners of Kolkata participated in this survey who were Hindustani Raga musicians, devoted students of HRM, or music connoisseurs with long listening experiences. The listening of 200 hours or more of Hindustani Raga Music was a common experience among these participants. These listeners gave their feedbacks after listening to successful recitals. The duration of the evaluated recitals was between 50 minutes to 90 minutes. Finally, the study included 69 listeners. These listeners took active part and rated the concerts. The assessed components include (1) different performance components, and (2) performance generated effects. The listeners rated each component on a 5 -point scale [ $\left[\begin{array}{ll}1 & \text { to }\end{array}\right]$, where 5 was excellent. The sample includes the participant audiences comprised of different age groups and with different levels of understanding and biases. Among the total participants, 55.26\% $(\mathrm{N}=42)$ reviewed their attended instrumental music concerts, and $44.73 \%(\mathrm{~N}=34)$ rated vocal music concerts. The data was analyzed using a pivot table. The study was conducted between November 2018 to March 2019, which was the pick concert season for famous music festivals in Kolkata.

\section{Results and Discussion}

\section{a. Roles of Different Parts of Hindustani Raga Music Performances in Generating Concert Impacts at different Levels}

This study was based on $\mathrm{N}=69$, i.e., the total number of cases studied was 69 . The focus of the study was to understand the relative impacts of different parts of Hindustani Raga Music [HRM] recitals. The different parts of renderings are the opening alap-jor-jhala part that is played without tablA support [WTS], slow part performed with tablA support [SP], and the final fast part with tablA support [FP]. The collected data indicated the relative impact levels of these three parts of a recital, namely WTS, SP, and FP, on the ratings of a concert by the listeners. The chart is showing the mean impact or rating values of three different stages of HRM recitals. 


\begin{tabular}{|r|r|r|r|}
\hline $\begin{array}{r}\text { Recital } \\
\text { rating }\end{array}$ & $\begin{array}{r}\text { AlAp-joR } \\
\text { without tablA } \\
\text { support } \\
\text { (mean) }\end{array}$ & $\begin{array}{r}\text { Slow } \\
\text { composition } \\
\text { part (mean) }\end{array}$ & $\begin{array}{r}\text { Middle or } \\
\text { fast } \\
\text { composition } \\
\text { part (mean) }\end{array}$ \\
\hline 3 & 2.92 & 3.08 & 3.88 \\
\hline 4 & 3.88 & 3.94 & 4.00 \\
\hline 5 & 4.31 & 4.06 & 4.47 \\
\hline
\end{tabular}

$3=$ Average, $4=$ Good and $5=$ Excellent for Concert ratings

Table -1

In this study, the average rated concerts [here rated as 3] is showing the mean of 2.92, 3.08, and 3.88 for areas without tablA support [WTS], Slow part [SP] and Fast part [FP]. The study indicates that FP has maximum impact in this area (3.88) when next is SP (3.08), and the lowest impact was from WTS (2.92).

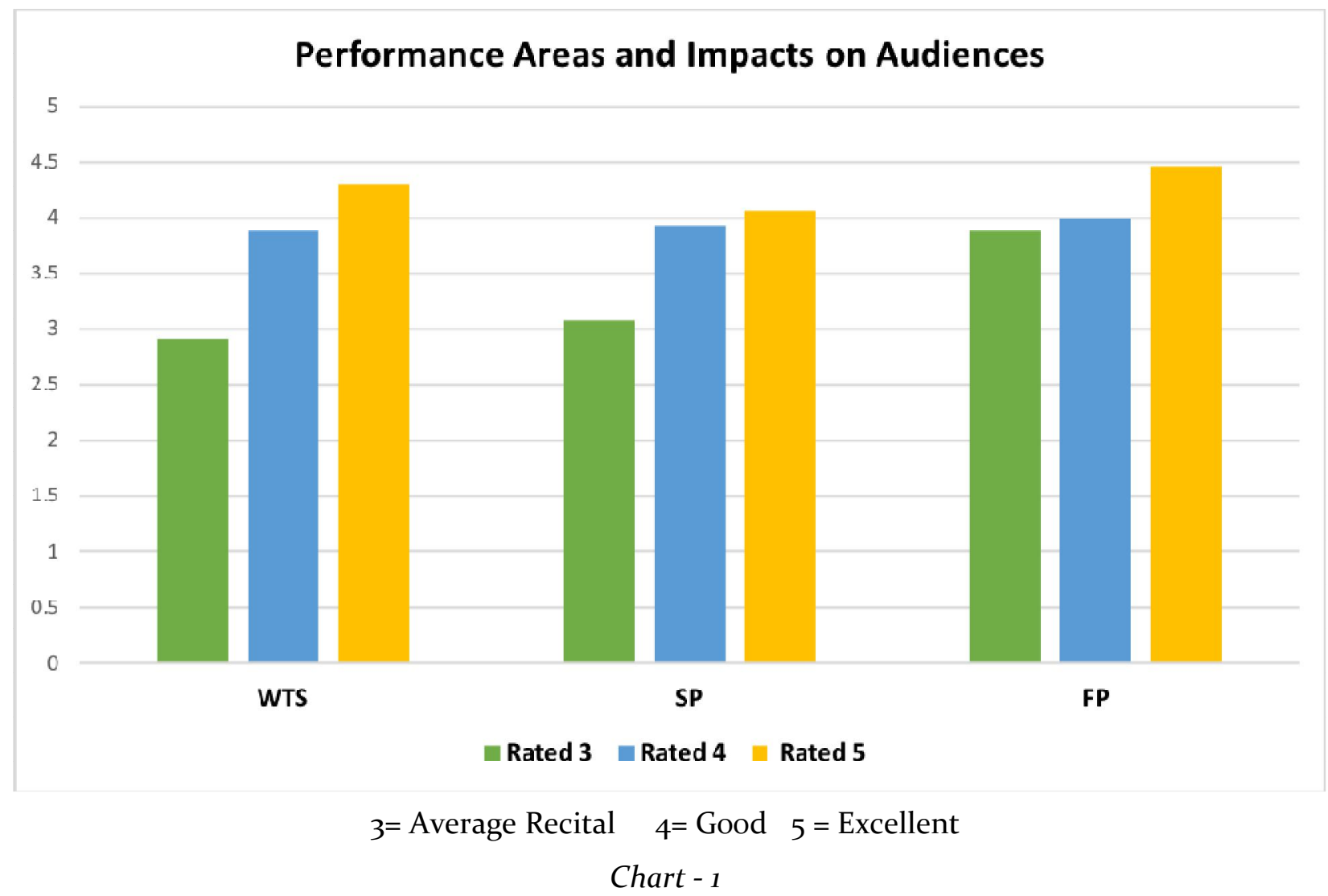

The good recitals that rated 4 in the five-point scale also are showing similar trends.

Interestingly the highest rated or excellent recitals are showing a different trend. Here we are seeing $\mathrm{WTS}=4.31, \mathrm{SP}=4.06$, and $\mathrm{FP}=4.47$. When fast performance consistently proved to be the 
most prominent influence factor for all the recitals [rated 3, 4, and 5], when areas without tablA support [WTS] have shown higher impact than the Slow tablA parts [SP] in recitals rated 5.

When we see the scores of the three different areas of the HRM recitals, we see a consistent higher rating in each of the areas with low to high recital ratings. That is, WTS is showing 2.92, 3.88, and 4.31 for recitals rated 3, 4, and 5, respectively. When SP or slow part is showing 3.08, 3.94, and 4.06 for concerts rated 3, 4, and 5, respectively. For FP or faster parts, the means rise like $3.88,4.00$, and 4.87 for ratings 3,4 , and 5 , respectively. The changes in means are as below:

\begin{tabular}{|l|l|l|l|}
\hline $\begin{array}{l}\text { Recital } \\
\text { rating } \\
\text { change }\end{array}$ & WTS & SP & FP \\
\hline 3 to 4 & +0.96 & +0.86 & +0.12 \\
\hline 4 to 5 & +0.43 & +0.12 & +0.47 \\
\hline
\end{tabular}

Table -2

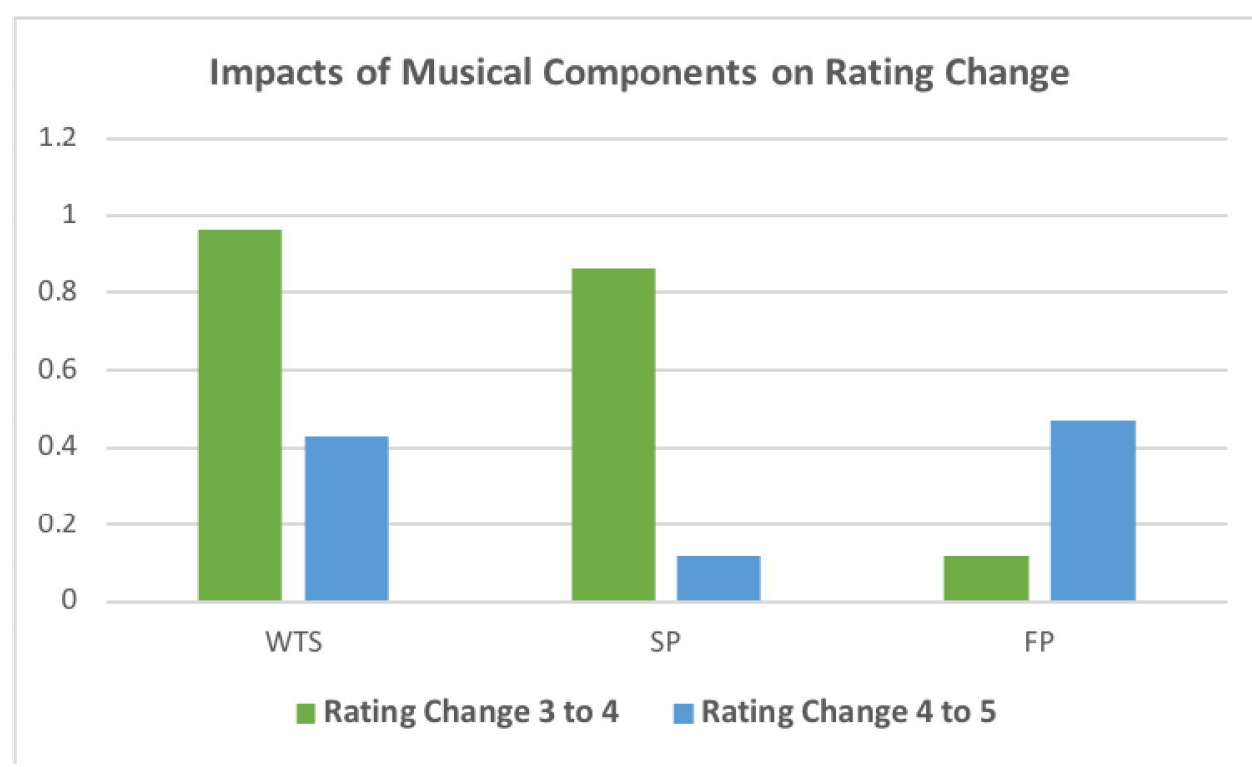

3 to $4=$ Average to Good $\mid 4$ to $5=$ Good to Excellent $\mid$ WTS=Without table support SP=Slow Part, FP=Fast Part

\section{Chart - 2}

From this chart, the most significant roles were played by WTS and SP with the changes by +0.96 and +0.86 , respectively. WTS and SP played significant roles in raising the concert rating from Average to Good with changes in means by +o.96 and +o.86, respectively. For uplifting the concert from Good to Excellent, the WTS and FP played significant roles with the raise in means by +0.43 and +0.47 , respectively. Also, we can see that the FP played a prominent role when boosting the rate from Good to Excellent when the other two factors WTS and SP played important roles from boosting the concert from Average to Good level.

The above study indicates the relative roles of WTS, SP, and FP in influencing the listeners' likings for a recital. 


\section{b. Impacts of the effects components on recital rating}

Considering the recital rating as 3, we can see that the impact levels of different effects can be put to the following order: (1) raga mood 3.00, (2) liveliness 2.94, (3) surprise and serenity are showing the same mean score 2.88 and (4) uniqueness at the lowest mean score as 2.44 .

Now let us see the impact levels of different effect components on creating the recital accepted at level 4. The effects with decreasing mean scores are (1) raga mood 4.15, (2) liveliness 3.9, (3) serenity 3.68 (4) uniqueness 3.66 , and (5) surprise 3.58 .

The recitals rates as 5 have the following effect impact distributions: (1) liveliness 4.41, (2) serenity $4.28,(3)$ surprise $4.18,(4)$ raga mood 3.88 , and (5) uniqueness 3.82.

\begin{tabular}{|l|l|l|l|l|l|}
\hline $\begin{array}{l}\text { Recital } \\
\text { rating }\end{array}$ & $\begin{array}{l}\text { Serenity } \\
\text { [mean] }\end{array}$ & $\begin{array}{l}\text { Surprise } \\
\text { [mean] }\end{array}$ & $\begin{array}{l}\text { Liveliness } \\
\text { [mean] }\end{array}$ & $\begin{array}{l}\text { Uniqueness } \\
\text { [mean] }\end{array}$ & $\begin{array}{l}\text { raga } \\
\text { mood } \\
\text { [mean] }\end{array}$ \\
\hline 3 & 2.88 & 2.88 & 2.94 & 2.44 & 3.00 \\
\hline 4 & 3.68 & 3.58 & 3.90 & 3.66 & 4.15 \\
\hline 5 & 4.24 & 4.18 & 4.41 & 3.82 & 3.88 \\
\hline & & & & & \\
\hline
\end{tabular}

Table -3

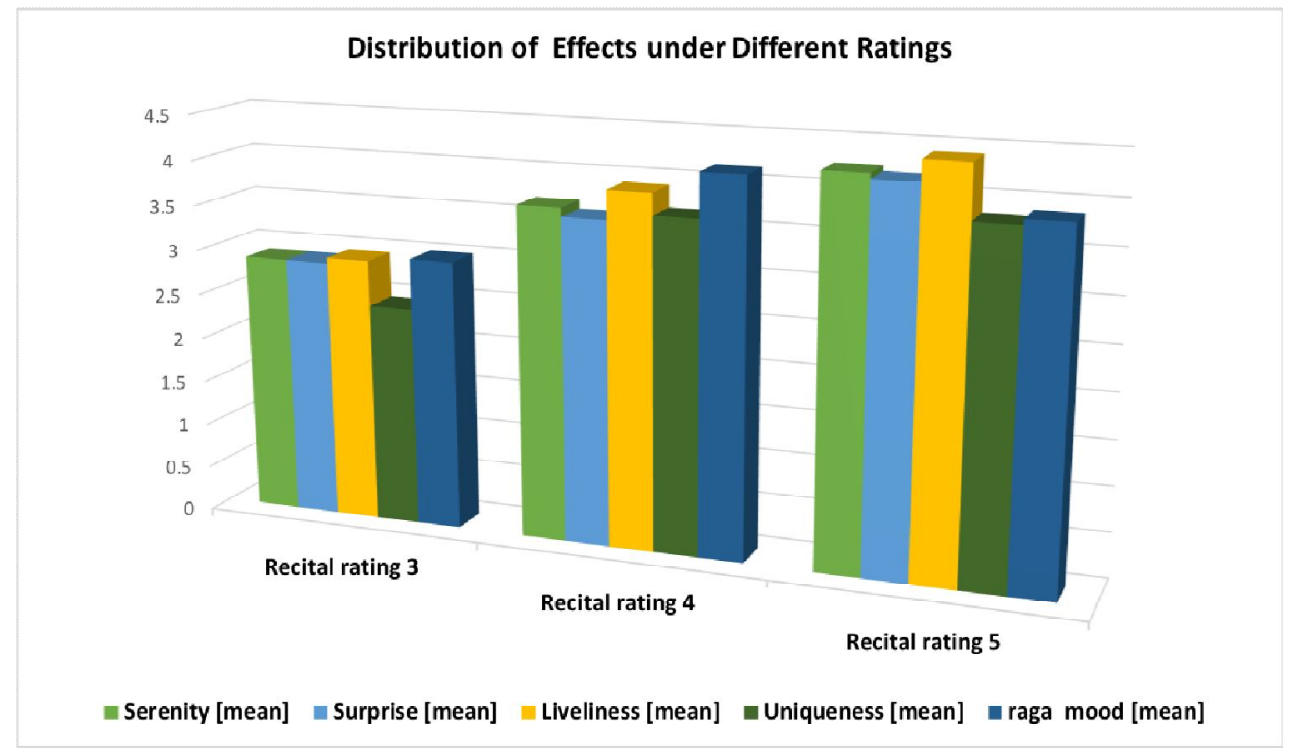

Series $1=$ Recital rating 3 Series $2=$ Recital rating $4 \quad$ Series $3=$ Recital rating 5

\section{Chart - 3}

If we consider recital or concert ratings 3, 4, 5, we can observe that all the effect components excepting the raga mood are showing an orderly increasing effect of impact means.

The raga mood components are showing some anomaly by showing the means as; recital rating 3 and raga mood 3.00, recital rating 4 and raga mood 4.15, and for the recital rating 5, the raga 
mood means is 3.88 . Therefore, the recitals with 5 ratings have lesser raga mood ratings than recitals with rating 4 .

The whole picture indicates that the listeners' focus when assessing a concert as excellent, they give lesser importance to the raga mood than other components like liveliness, or serenity. When serenity received lower priority for the recitals rated 3 and 4 , as can be seen in the comparative score of different effect components, it received higher priority for recitals rated as 5 . The most noticeable effect for the recitals rated 3 and 4 is 'raga mood'; those are showing 3.00, and 4.15 mean scores, respectively. Interestingly the highest-rated recitals with 5 are showing liveliness as the most important effect component with mean score 4.41 followed by serenity as 4.24 .

\begin{tabular}{|l|l|l|l|l|l|}
\hline $\begin{array}{l}\text { Recital } \\
\text { rating } \\
\text { changes }\end{array}$ & $\begin{array}{l}\text { Serenity } \\
\text { [mean] }\end{array}$ & $\begin{array}{l}\text { Surprise } \\
{[\text { mean] }}\end{array}$ & $\begin{array}{l}\text { Liveliness } \\
{[\text { mean] }}\end{array}$ & $\begin{array}{l}\text { Uniqueness } \\
{[\text { mean] }}\end{array}$ & $\begin{array}{l}\text { Raga } \\
\text { mood } \\
{[\text { mean] }}\end{array}$ \\
\hline 3 to 4 & +0.80 & +0.70 & +0.96 & +1.22 & +1.15 \\
\hline 4 to 5 & +0.56 & +0.60 & +0.51 & +0.16 & -0.28 \\
\hline
\end{tabular}

Table - 4

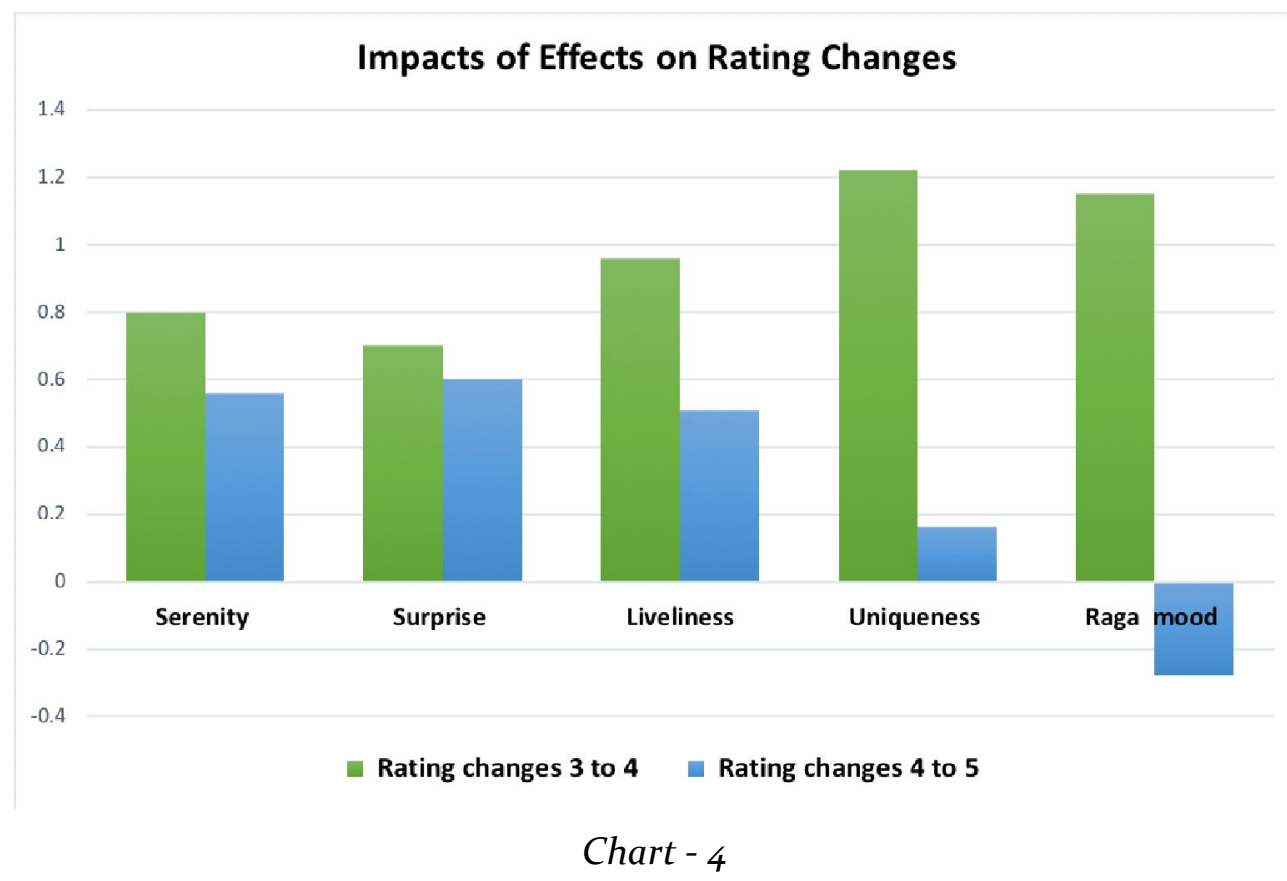

When studying the differences of means in references to the recital rating changes, we can see that for changes from rating 3 to 4 , the most prominent factors are uniqueness $(+1.22)$ and raga mood $(+1.15)$. However, interestingly for rating recital changes from 4 to 5 , we see the most prominent positive changes as the surprise (+o.6o) and serenity (+o.56) when Raga mood showed a negative trend (-0.28). It indicates that at the level when raga mood reached a mean of 3.88 (as in recitals rated as 5), the listeners no more put enough importance on raga moods and feel the changes on other effects. When for very good performance, it is important to generate uniqueness and be faithful towards raga mood until it reaches a good height. Nevertheless, for excellent 
performances after reaching certain heights in all the effect areas, the listeners are more prone to feel the differences in surprise and serenity.

\section{Conclusions}

The research study has solely focused on the selective listening of Hindustani Raga Music Performance, where, for obvious reasons, the number of listeners and connoisseurs were not too large. Given this micro scenario, the study attempted to demarcate the factors that are responsible for making a performance successful. A typical successful Hindustani Raga Music performance comprises an optimized balance of the technical, musical, and extra-musical factors. The present study clinically examined all the aspects separately. The Slow part (SP) is equally appealing as the thrilling Fast Part (FP). In a recital, the part without tabla can be equally aesthetically pleasing as the part with tabla. It is the artist's chosen musical applications and the connoisseurs' experience and the realization that give shape to the raga presentation and determine the success of a concert. Hence, the results give insights to music practitioners and aspiring musicians to incorporate in their performances. Lastly, the findings have broader implications in the field of musical studies and advanced training.

\section{Notes}

\footnotetext{
${ }^{\mathrm{i}}$ Hindustani Raga Music (HRM) is also known as Indian Classical Music.

ii Teaching and learning process in Hindustani Raga Music is called talim. This is an Arabic word for education and institution.

${ }^{i i i}$ Raga is a melodic framework over which the entire aesthetical exposition is done in Indian Classical Music.

${ }^{\text {iv }}$ When the listening is important for the audiences, it is important that the musicians also can listen to their own renderings on stagenicely.

vkhayAl is one of the vocal music genres of Hindustani Raga Music. The word Khayal originated from the Arabic word khayal which mean "Imagination". This vocal form is based on the free improvisation of the raga . Khayal singing is accompanied with tabla.

${ }^{\text {vi }}$ A short alap is called aochar. This is mostly sung in khayal performances before starting the composition. $A o c h A r$ is done without tablAsupport. The instrumentalists also at tmes play AocAr.

viiHere vistAr means slow elaborations.

viii Slow composition in khayaAl singing.

${ }^{\text {ix }}$ tAna and vistAr are literally synonyms. But, tAnas are commonly and traditionally understood as fast to very fast passages.

${ }^{\mathrm{x}}$ There are controversies whether the instrumental music opted the alap sequences from Dhrupad or the Dhrupad style opted from the Veena.
} 


\section{Works Cited}

Moran, N. (2013). Social Co-Regulation and Communication in North Indian Duo Performances. In B. D. Edited by Martin Clayton, Experience and Meaning in Music Performance (pp. 40-61). New York: Oxford University Press.

Pitts, S. E. (2005). What Makes an Audience? Investigating the Roles and Experiences of Listeners at a Chamber Music Festival. Music E Letters .Vol-86.No-2, 257-269.

Bennett, L. (2012). Music Audiences: An Introduction. Journal of Audience and Reception Studies, Vol 9, Issue 2, 200-205.

Wise, J. S. (2016). Going to a Classical Concert: the Relationship between Audience Perceptions of Artistic Identity and Motivation for Future Attendance. London: Queen Mary University of London.

Fernandez-Blanco, J. P.-R. (200o). Are Popular and Classical Music Listeners the Same People? Journal of Cultural Economics vol 24, 147-164.

Martinez, J. L. (2001). Semiosis in Hindustani Music . Delhi: Motilal Banarsidass Publishers.

Eggebrecht, H. H. (2010). Understanding Music: The Nature and Limits of Musical Cognition. England: Ashgate.

Feld, S. (1984). Communication, Music, and Speech about Music. International Council for Traditional Music Vol 16, 1-18.

Palmer, C. (1997). Music Performance. Annual Review of Psychology, 48, 115-138.

Sloboda, J. A. (2000). Individual Differences in Music Performance. Trends in Cognitive Sciences -Vol 4, No 10, 397--403.

Wright, Matthew \& Wessel, D. (1998). An Improvisation Environment for Generating Rhythmic Structures Based on North Indian "Tal" Patterns. Center for New Music and Audio Technologies. Retrieved June 16, 2020, from http://cnmat.org/ICMC98/papers-html/wright-wessel-tal-demo.html

Moran, N. (2011). Music, bodies and relationships: An Ethnographic Contribution to Embodied Cognition Studies. Psychology of Music, 41(1) 5-17.

Juslin, P. N. (2003). Five Facets of Musical Expression: A Psychologist's Perspective on Music Performance. Psychology of Music, 273-302.

Christopher D. Azzara Alden H. Snell, I. (2016). Assessment of Improvisation in Music. Oxford Handbooks Online.

Thom, P. (2003, April). The Interpretation of Music in Performance. The British Journal of Aesthetics, 43 (2), 126-137.

Abbé-Decarroux, F., \& Grin, F. (1992). Risk, Risk Aversion and the Demand for Performing Arts. (R. Towse, \& A. Khakee, Eds.) Cultural Economics, 121-140.

Baumol, W., \& Bowen, W. (1966). Performing Arts - The Economic Dilemma. New York: The Twentieth Century Found. 